\title{
The Role of a Pharmacist and Undergraduate Pharmacy Education with Special Reference to the Adverse Drug Reaction Reporting System in
} Japan

\section{Michiko Yamamoto*}

Education Center for Clinical Pharmacy Practice, Showa Pharmaceutical University, Tokyo, Japan

Over the past decades, Japan has experienced several drug-induced disasters, and so, the improvement in drug safety measures containing risk communication has become an important issue [1]. In Japan, Risk Management Plan (RMP) has begun in April, 2013 which is seven years behind as compared to the most Western countries [2]. RMP consists of three elements: Safety Specification, Pharmacovigilance (PV) Plan and Risk Mitigation Plan. Although the drug companies undertake the duties for RMP, the pharmacists in the clinical spots are expected to take part and contribute to RMP more actively. In order to meet the expectation, systematic learning of the framework, structure, and view of drug safety in the clinical education at undergraduate level of pharmacy is essential.

$\mathrm{PV}$ is the most important issue as it forms the foundation of the framework of safety. According to WHO, PV is defined as the science and activities relating to the detection, assessment, understanding and prevention of adverse effects or any other drug-related problem. Spontaneous Adverse drug reaction (ADR) reporting in PV is an important measure of signal detection, in addition to being highly costeffective. Furthermore, it is powerful as the method of detecting safety concerns in relation to drugs and it plays a pivotal role in PV. Therefore, one can say that ADR reporting is the frontline defense system to ensure drug safety. On the subject of the safety of newly approved drugs, collection of post-marketing safety information is extremely important owing to several reasons such as:

i. the drug reactions documented during clinical trials are insufficient to evaluate ADRs completely,

ii. there is a tendency for approval review time to be shortened,

iii. the high prevalence of OTC drug usage, and

iv. high withdrawal cost of the drugs relevant to the ADR, etc.

However, in Japan, spontaneous reporting number of ADR from pharmacists remains low. According to annual statistics in UK, approximately $16 \%$ of ADRs were reported from hospital pharmacists and community pharmacists in the individual reports [3]. Since they are estimated to be about $60 \%$, the reports from the pharmacists considered to be approximately $10 \%$ among all reports including reports from pharmaceutical companies. While in Netherlands, the reports from pharmacists were about $12 \%$ in whole reports [4]. On the other hand in Japan, the reports from the medical staff were about $10 \%$ among all during 2010 and 2012 [5-7], and contribution of the pharmacists has been accounted for 40-50 percent indicating that it is only $4-5 \%$ of the whole [5]. There seem to be several reasons for this. Firstly, drug dispensing activities have occupied a large part of pharmacist's work in Pharmacies and there is no system to nourish the technicians who bear such jobs in our country unfortunately. Secondly, in Japan, the pharmacists are not trained sufficiently to involve in medications to patients. Thirdly, since many drugs are often prescribed simultaneously, identification of adverse effects might be more difficult to accomplish in Japan.
However, the global needs to evaluate risk-benefit balance of drugs are increasingly obvious throughout their total life cycle, from development of the drug up to its marketing. Due to such circumstance, 7 years ago, the educational period at the undergraduate school of pharmacy was extended from four to six years in Japan. Thus, it has become clear that a larger responsibility and a more crucial role are expected from the pharmacists to give safe and effective medications to the public. Among several drug-induced disasters we have experienced, one of the most serious worthy of mention is infection with hepatitis $\mathrm{C}$ virus (HCV) by contaminated fibrinogen preparation. As a response to this issue, the official committee was established for investigation of the cause of HCV infection. With the support of the public, the committee decided to strengthen "Ensuring the safety of pharmaceuticals" in undergraduate pharmacy and medical education [8]. This will become the beginning for Japanese pharmacists to bear drug safety issue more actively and responsively. Sweis and Wong [9] conducted a study in Western countries by issuing questionnaire to hospital pharmacists inquiring about the factors which influence ADR reporting, and their results suggested how to increase the knowledge about adverse effects, or a program of instruction to suggest the pharmacists regarding proper ADR reporting. Sullivan has reported a possibility to increase the reports by urging students to get involved more actively in adverse effects program and to perform a detailed investigation of the suspected ADR cases [10,11]. Sears and others also claim that it should be continued and examined to strengthen the educational program about an ADR report to a student11). Considering that PV is the need of the hour in ADR reporting system, and that enough time is not spent for PV in the undergraduate pharmacy in UK, Smith's and others requested the need to increase its education time for students [12].

In the present situation, the contribution of pharmacists is highly expected in drug safety, and ADR reporting is becoming increasingly important as their primary role. Therefore, it is strongly recommended that the time of PV education should be expanded in Japan, and students should learn more practically and systematically now.

With reference to ADR, it is not only essential to identify, but also, to verify from pharmacological viewpoints (e.g. the pharmacological profile of drugs, structure-activity relationship, etc.). A pharmacist is in the advantageous position to find ADR from a pharmaceutical aspect

${ }^{*}$ Corresponding author: Michiko Yamamoto, Education Center for Clinical Pharmacy Practice, Showa Pharmaceutical University, Tokyo, Japan, Tel: +81-42 721-1511; E-mail: m-yamamoto@ac.shoyaku.ac.jp

Received Aug 20, 2013; Accepted Aug 22, 2013; Published Aug 24, 2013

Citation: Citation: Yamamoto, (2013) The Role of a Pharmacist and Undergraduate Pharmacy Education with Special Reference to the Adverse Drug Reaction Reporting System in Japan. J Pharmacovigilance 1: e113. doi:10.4172/2329-6887.1000e113

Copyright: ( 2013 Agrawal P. This is an open-access article distributed under the terms of the Creative Commons Attribution License, which permits unrestricted use, distribution, and reproduction in any medium, provided the original author and source are credited. 
Citation: Yamamoto, (2013) The Role of a Pharmacist and Undergraduate Pharmacy Education with Special Reference to the Adverse Drug Reaction Reporting System in Japan. J Pharmacovigilance 1: e113. doi:10.4172/2329-6887.1000e113

Page 2 of 2

since they are drug specialists. In a nut shell, a systematic education which covers the basic, pharmacological and clinical knowledge about ADR will form the foundation for a pharmacist to effectively contribute to PV. Fortunately, the recent trend for pharmacists to be involved in clinical work more frequently has made the systematic approach easier. Pharmacists not only report the adverse drug reactions by themselves, but also, will help the patients to report their ADR, if any, to a regulatory agency directly, and as a whole, this will also contribute to the signal detection since the number of patient reports increases further.

In conclusion, pharmacists have a social responsibility to perform $\mathrm{ADR}$ reporting and it is considered as one of their important duties. To achieve this goal, students at the Pharmacy school should be provided a suitable educational condition to learn these more appropriately. By strengthening PV education at undergraduate level, it is expected to bring up talented pharmacists in the near future, who can identify ADR properly, as well as to increase the number of ADR reports and ensure drug safety.

\section{References}

1. Yamamoto M, Nakayama T (2008) A Comparative Study of the Communication of Drug Safety Information by Governmental Agencies in Japan and Western Countries: The Case of Asthma Medications. Drug Inf Journal 42: 583-596.

2. Notice from Ministry of Health, Labour and Welfare (2012) Guideline of Risk Management Plan.
3. MHRA annual statistics 2011/12.

4. Lareb Jaarbericht 2012.

5. The Pharmaceuticals and Medical Devices Agency Annual Report FY 2010 Japan.

6. The Pharmaceuticals and Medical Devices Agency Annual Report FY 2011, Japan.

7. The Pharmaceuticals and Medical Devices Agency Annual Report FY 2012, Japan.

8. Proposal for Administrative Reform in Preventing Recurrence of Drug-induced Incidents by committee of investigation for the fibrinogen-induced Hepatitis C infection in Japan (2012).

9. Sweis D, Wong IC (2000) A survey on factors that could affect adverse drug reaction reporting according to hospital pharmacists in Great Britain. Drug Sa 23: $165-172$.

10. Sullivan KM, Spooner LM (2008) Adverse-drug-reaction reporting by pharmacy students in a teaching hospital. Am J Health Syst Pharm 65: 1177-1179.

11. Sears EL, Generali JA (2005) Adverse drug reaction and medication error reporting by pharmacy students. Ann Pharmacother 39: 452-459.

12. Smith MP, Webley SD (2013) Pharmacovigilance teaching in UK undergraduate pharmacy programmes. Pharmacoepidemiol Drug Saf 22: 223-228. 